\title{
A computer game to help people understand the energy performance of buildings
}

Panagiotis Patlakas DipEng (MEng), MArchStudies, CEng, MICE Associate Professor in Civil Engineering, Faculty of Computing, Engineering and the Built Environment, Birmingham City University, Birmingham, UK (corresponding author: panagiotis.patlakas@bcu.ac.uk)
Rokia Raslan BSc (Hons), MSc, PhD

Lecturer in Environment Design and Engineering, Institute for Environmental Design and Engineering, The Bartlett, University College London, London, UK

Building users play an important role in determining the energy use of a specific building. Indeed, their behaviour could be one of the reasons behind the energy 'performance gap' observed in many buildings. Moreover, informed building users can promote the sustainability agenda through their consumer choices. This, however, raises the issue of understanding the energy performance of buildings. This paper presents an exercise on developing and testing a computer game which introduces players to the basic concepts of building energy performance. A software application was developed to visualise post-occupancy evaluation data in a dynamic three-dimensional context. A pilot study was used for assessing and fine-tuning the methodology, followed by the main study of two workshops with two different user groups: non-experts and entry-level specialists. The results are presented using both quantitative and qualitative approaches. The findings suggest that the advantages and challenges of 'gamification' described in the literature are generally confirmed by the tentative evidence of this exercise. In addition, the process highlights the potential of novel ways of presenting building data in enabling more stakeholders to engage with the issue of building energy performance.

\section{Introduction}

Sustainability researchers can be confident that their discipline has never enjoyed such widespread attention and been assigned so much importance. The significance of the topic extends outside the built environment scientific and technical community, with a number of leading international policymaking bodies, most notably the United Nations (UN), placing it at the forefront of concerns (IPCC, 2014). This has been accompanied by a number of subsidies and other policymaking tools to support environment-friendly design and other pro-sustainability solutions (Kibert, 2002). In the architectural, engineering and construction (AEC) sector, sustainability has turned into a key issue in both research and practice, encompassing all fields (Cruickshank and Fenner, 2007; Ortiz et al., 2009; Szolokay, 2014). In AEC education, sustainability issues have achieved prominence in many curricula (Murray and Cotgrave, 2007; Wright, 2003), while a range of postgraduate courses in sustainability are widely available in academic institutions across the globe.

However, despite the generally wide support and the amount of resources and brainpower devoted to the issue, the approach described earlier, which focuses on policymaking and 'upskilling' the technical community, has not always been able to deliver the intended outcomes. The current practice standard for achieving sustainability typically relies on satisfying the requirements of specific environmental rating systems, such as the Building Research Establishment Environmental Assessment Method (Breeam) and the Leadership in Energy and Environmental Design (Leed). However, the adoption of these by the built environment community has been far from complete: they can be perceived as complex and inflexible and with issues with regard to the way they attribute scores (Ding, 2008). Even when these methods are applied in full, the actual performance of the building might not live up to the one originally intended. The term 'credibility gap' was first used more than a decade ago to describe the difference between the design expectations and the actual energy use of a building (Bordass, 2004). Today this has been established as an accepted reality, with the term 'performance gap' being the most commonly employed to describe the phenomenon (De Wilde, 2014).

This gap can be attributed to a host of reasons. First, environmental design relies on digital building performance simulation (BPS) tools, whose effectiveness and consistency have often been shown to be problematic (Schwartz and Raslan, 2013). Nonetheless, other engineering disciplines have successfully addressed similar issues in the past: the twin issue of validation and verification, where the mathematical model used in calculations (validation) and the data generated by this model (verification) meet the required criteria for acceptance, appears in the vast majority of methods employed in civil and mechanical engineering (Szabó and Babuška, 2011). This is typically achieved through an iterative process, where the model is checked against existing data. There are, however, two key differences that differentiate environmental design for the built environment from other engineering endeavours.

First, environmental design researchers, on whose work BPS tools are based, lack the amounts of data that are available to other researchers. Only a small subset of completed buildings are monitored for environmental performance once put in use, usually only when there is specific research interest, such as the provision of observational data to provide the basis for descriptive or stochastic methods that can be incorporated in BPS applications (Yan et al., 2015). Even then, these studies are often impacted by various limitations that may limit their representativeness and 


\section{Offprint provided courtesy of www.icevirtuallibrary.com Author copy for personal use, not for distribution}

applicability. For example, monitoring may often involve a limited number of case study buildings, may take place only for small periods of time, which may not be representative of seasonal variations, or might be subject to a range of technical problems that may impact consistency, accuracy of data collection and the robustness of the analyses (Swan et al., 2015).

As such, the importance of post-occupancy evaluation (POE) surveys and their fundamental role in closing the aforementioned loop cannot be understated. Menezes et al. (2012) showed how POEs can be used to address the performance gap, while Bordass and Leaman (2005) called for POEs to become a routine part of project delivery over a decade ago. While the benefits are obvious, a key barrier that was identified early on in environmental design research is that most clients do not see a direct benefit from a POE, which creates what is referred to as 'fragmented incentives' (Zimmerman and Martin, 2001). From their perspective, and in terms of a strictly business view, there is no legal requirement to conduct one and, additionally, the results could reveal design flaws that a developer might prefer to remain hidden.

\section{The role of the building user}

\subsection{The issue of user behaviour}

The second challenge for sustainability-conscious designers and environmental design researchers is the issue of user behaviour. In the built environment, energy consumption is closely linked to occupant presence, interaction and behaviour. Studies have suggested that the impact of user behaviour on the energy performance of a building significantly exceeds that linked to the thermal process within the building facade and is a major contributing factor to uncertainty of building performance (Hoes et al., 2009). The assumptions made by environmental designers during the planning and design stage often differ widely from how the building is utilised once delivered and put to actual use. For example, research into uncertainty in occupant behaviour in building energy models found that the energy consumption can increase by more than $150 \%$ compared to predicted values (Clevenger and Haymaker, 2006) and has highlighted that user behaviour significantly affects energy consumption model predictions, even if other variables such as the weather conditions, the building envelope and the equipment were well defined (Yan et al., 2015). The precise reasons for this are unclear and often differ from case to case. Possible reasons include unrealistic assumptions of user behaviour, inadequate building performance, a lack of understanding on how individuals make decisions or simply users lacking an incentive to conform to the design assumptions (Bourgeois et al., 2006; De Wilde and Tian, 2009; Gill et al., 2010; Santos Silva and Ghisi, 2014).

\subsection{The user as consumer: insights from other fields}

In the past two decades, as the issue of user behaviour has progressively achieved prominence, there have been many attempts to educate building users with regard to their energy use (Fink, 2011; Hui and Cheung, 1999). More recent efforts have utilised digital visualisation in various forms (Boomsma et al., 2016; Chen et al., 2012). It is interesting, however, that this work has been driven by a desire to educate users as a self-evident good and as disconnected from the design stage. The idea of the building user as a consumer who, when better informed, can influence the real estate market and thus the design options available has attracted less (if any) attention in the policy debate.

The relatively limited information on a building's post-occupation actual performance exacerbates a situation that economists would describe as 'asymmetric information' between building producer and consumer. Asymmetric information refers mainly to the fact that building developers are much more knowledgeable about the characteristics of constructed buildings than consumers are (Akerlof, 1970). The consequence is that 'market failure' may ensue, and mutually beneficial transactions might be lost relative to the full information benchmark (Stiglitz and Brown, 2000). The problem has been thoroughly examined in several domains: the insurance industry (Finkelstein and Poterba, 2004), the financial industry (Karlan and Zinman, 2009) and other markets. However, in the construction industry, research is lacking; thus, valuable insights from theories of asymmetric information have not been sufficiently utilised (Sorrell, 2003). This neglect contributes to a very undesirable state of affairs, as inefficiencies stemming from asymmetric information seem to be rampant in the UK construction industry (Sorrell, 2003).

This entails serious policy implications. If asymmetric information is prevalent and consumers are not sufficiently informed about the consequences of their market behaviour, their rights will be insufficiently protected. Producers may generally not have an incentive to provide adequate information and state intervention is required (Milgrom, 2008). In terms of optimal consumer protection regulation, information requirements are preferable to 'direct regulation' (Loewenstein et al., 2014). From an economist's perspective, information is critical to both allowing for personal initiative and enabling the smooth operation of a free housing market. However, so far, the main focus of both research and industry has been targeting the supplier side. Considerable effort has gone into research purporting to inform engineers, designers, building developers and government regulators with regard to the fundamentals of the environmental properties of buildings.

Technology has a large role to play in informing consumers. The authors posit that sustainability can be greatly enhanced by allowing the consumer systematically to evaluate the relevant aspects of the built environment (thermal comfort, energy use, etc.) and to incorporate this evaluation in the purchasing decision. This might ameliorate any problems of asymmetric information in the market. The authors are confident that this may facilitate a 'market-based approach' to the sustainability problem, in the spirit of 'nudging' (Thaler and Sunstein, 2008), rather than a strictly regulatory one. Advocating this approach is based on the principle that, in the absence of externalities, informed consumers can offer 


\section{Offprint provided courtesy of www.icevirtuallibrary.com Author copy for personal use, not for distribution}

valuable insights into which sustainable options should be built and how. In addition, consumers are more likely to provide suitable guidance for user preferences than regulators are. The current state of affairs has a strong paternalistic flavour. It is well known that excessive reliance on regulatory solutions brings the risk of rent-seeking and lobbying by special interests (Grossman and Helpman, 2001). Moreover, human attention is limited, and some modes of communicating information are more compatible with human processing than others are (Loewenstein et al., 2014). Accordingly, simplifying and conveying information in an accessible way can make a great difference to how consumers assess this product.

This implies a fundamental change of view of the user compared to existing approaches: the building user (or other non-expert stakeholder) should not aim to understand simply how his/her choices affect energy consumption for a given building; s/he should aim to understand how different buildings perform given certain conditions. These better-informed users then, in their function as building consumers, can influence the market and thus the environmental design quality of buildings.

This ambition, however, poses the question of how users can be better trained in understanding building performance. In a previous work, the authors demonstrated how, given certain parameters, dynamic three-dimensional (3D) (i.e. fourdimensional (4D)) in-context visualisation can allow for a better understanding of POE data compared to existing methods, among both expert and non-expert users (Patlakas et al., 2014). Here the authors present the introduction of game-playing elements for the same purpose.

\section{The role of game playing}

\section{1 "Gamification" as an educational tool}

In recent years, so-called gamification - including serious games and ludic simulations - has attracted increasing attention. Applications of gamification have been reported by scholars in fields as diverse as marketing (Huotari and Hamari, 2012), risk management (Bajdor and Dragolea, 2011), healthcare (King et al., 2013; McCallum, 2012) and software engineering (Pedreira et al., 2015). Gamification has received particular interest by researchers in education and training, covering practically all fields: primary (Simões et al., 2013), secondary (Attali and Arieli-Attali, 2015) and higher education (HE) (Barata et al., 2013); e-learning (Muntean, 2011); military training (Arenas and Stricker, 2013); and employee training (Landers and Callan, 2011).

In the built environment, gamification has been of particular interest to researchers specialising in the different facets of architectural computing, often with emphasis on collaborative and participatory activities: Aydin et al. (2014) employed it in the context of shape grammars for mass-housing design, while more recently Savov et al. (2016) employed it for facade design. Its importance for educating both specialised users and laypeople has also been of interest: Bertuzzi and Zreik (2011) applied mixedreality games to raise awareness of cultural heritage issues; Chang (2004) employed design puzzles to support design learning; and later on Liang and Chang (2006) expanded the concept with the DiGame design game. In the more specialised field of environmental design, sustainable energy use has been a focus, as described by Gustafsson et al. (2009) and Cohen et al. (2013). Yan and Liu (2007) combined it with building information (BIM) elements to enhance sustainable design education.

Assessments of the impact and benefits of gamification are generally positive. Erenli (2013) found that the gaming industry has had a 'huge' impact on society and gamification can contribute effectively to teaching; Kapp (2012) stated that the research consensus is largely that appropriately designed games can be beneficial as learning tools for both adolescents and adults. Others give generally positive, but more nuanced accounts: a comprehensive review of the literature by Hamari et al. (2014) found that gamification generally does work; however, the gamified context and the qualities of the users were confounding factors that could affect the end result. In fields outside education, scholars have been less enthusiastic: Mollick and Rothbard (2014) found that gamification can have a positive impact on the affective experience of employees; however, it is important that consent and a sense of individual agency is maintained and the games do not stray into the paradox of management-dictated 'mandatory fun'. Although the authors concentrated on the workplace context, one can easily identify similarities of this caveat in the context of an educational institution, if the gamified processes are a curriculum requirement.

More critical positions exist, most famously that of Bogost (2015), who drew on Frankfurt (2005) to present gamification as a coercive strategy that is not concerned with 'truth' and whose successes are largely tautological; he goes further to suggest the term 'exploitationware' as a synonym for gamification, in order to highlight the fact that the game designer is trying to extract value by encouraging meaningless engagement. While Bogost targets largely corporate and marketing gamification (besides a philosopher and academic, Bogost is an established game designer himself), aspects of his critique certainly apply on all attempts at gamification. Particularly relevant is the charge of ambiguity of the term 'gamification', which can impact on the framework of the game design itself.

Among scholars, a precise definition of gamification remains elusive: an oft-cited take describes it as the use of video game elements in non-gaming systems in order to improve user experience and engagement (Deterding et al., 2011). The fundamental flaw of this is, however, obvious as it simply pushes the burden of definition to the concept of a 'game'. A highly comprehensive survey and analysis by Huotari and Hamari (2012) found no conditions that can be said to apply uniquely to games. The definition of gamification that the authors have devised for the purposes of this work draws from both Koster (2013) and 


\section{Offprint provided courtesy of www.icevirtuallibrary.com Author copy for personal use, not for distribution}

Salen and Zimmerman (2004), but expands these definitions by including the underlying aim of gamification, acknowledging Bogost's criticism. Specifically, the authors define gamification as

the development of a system in which players engage in a set challenge with defined rules, aiming to arrive at an identifiable outcome; the underlying aim of the system is for the developers to achieve specific results from the players' engagement, unrelated to the outcome, which might or might not affect the players.

Under this definition, then, what is required is the development of a suitable system with an appropriate challenge and the establishment of such rules and potential outcomes that the players' engagement with the system will produce the intended results.

\section{Development of a building performance game}

4.1 Aim of the gamification system

Drawing from the definition, mentioned earlier, the authors wanted to engage in a gamification exercise which would produce a number of results that would affect both them as developers and the players. These intended results are summarised in Table 1.

The requirements for achieving these results are summarised in Table 2.

\subsection{The EnViz software application}

The EnViz tool is a prototype software application developed by one of the authors as part of a research programme. It visualises temperature and relative humidity data in a $4 \mathrm{D}$ context of volumetric 3D models over time (Figure 1). The standard usability process consists of input of a building model; input of data logger output; selection of timescale and time ratio; and (optional) selection of desired thermal comfort criteria. The user can then see static (3D) and dynamic (4D) visualisations of the respective data (Figure 2) based on predefined colour maps. EnViz also supports the introduction of pass-fail criteria (e.g. specific ranges of temperature and humidity) and visualises the
Table 2. Actions for achieving game results

\begin{tabular}{|lc|}
\hline Action & $\begin{array}{c}\text { Corresponds to } \\
\text { objectives }\end{array}$ \\
\hline Use EnViz as a key part of the game & $2(a), 2(b)$ \\
Compare POE data comprehension in \\
EnViz with POE data comprehension in \\
2D charts and graphs \\
$\begin{array}{l}\text { Use POE data to make judgements on } \\
\text { building performance }\end{array}$ \\
$\begin{array}{l}\text { Use POE data tools as decision support } \\
\text { systems }\end{array}$ \\
$\begin{array}{l}\text { Provide players with a post-game } \\
\text { questionnaire to gauge their views on } \\
\text { the experience; supplement this with } \\
\text { (optional) small feedback sessions }\end{array}$ \\
\hline
\end{tabular}

spaces that pass or fail these checks at any given time in the data space.

The application was developed in Java Standard Edition 7, utilising the OpenGL programming interface, as implemented in the Lightweight Java Game Library. The model input format is Collada, an open-source text-based format for 3D graphics, while the data logger input can be either through XML or directly through comma-separated values (.csv) and Microsoft Excel (.xlsx) files.

The tool is intended to provide the benefits of large data set visualisation, including enhancing comprehension, enabling multiscale evaluation and facilitating hypothesis formation (Ware, 2012) for POE data analysis. In order to validate the effectiveness of EnViz, a 2-year usability testing programme was undertaken. Usability testing is generally viewed as an aspect of human-computer interaction. A major part involves field testing with non-expert users, ideally with controlled experiments that allow the collection of both quantitative and qualitative data (Te'eni et al., 2007). A typical approach is to measure parameters such as response time, response accuracy and mental effort (Huang et al., 2009).

Table 1. Intended results from the gamification exercise

\begin{tabular}{|c|c|c|}
\hline Beneficiary & Intended result & Objectives \\
\hline Developers & 1. Further undergoing research programme & $\begin{array}{l}\text { (a) Gain insights into the respective merits of two- } \\
\text { dimensional (2D), 3D and 4D modes of communication } \\
\text { of POE data among expert and non-expert users }\end{array}$ \\
\hline Developers and players & $\begin{array}{l}\text { 2. Introduction of a new innovative tool } \\
\text { into the teaching and learning process }\end{array}$ & $\begin{array}{l}\text { (a) Introduction of the Environmental Visualisation (EnViz) } \\
\text { tool to the process } \\
\text { (b) Awareness of ongoing research programme of tutors, } \\
\text { with possible opportunities for research topics }\end{array}$ \\
\hline Players & 3. Further subject knowledge & $\begin{array}{l}\text { (a) Introduction to the fundamentals of decision support } \\
\text { systems for environmental design } \\
\text { (b) Better understanding of how environmental design } \\
\text { affects performance over the building life cycle } \\
\text { (c) Better understanding of how facilities managers have to } \\
\text { make decisions }\end{array}$ \\
\hline
\end{tabular}




\section{Offprint provided courtesy of www.icevirtuallibrary.com Author copy for personal use, not for distribution}

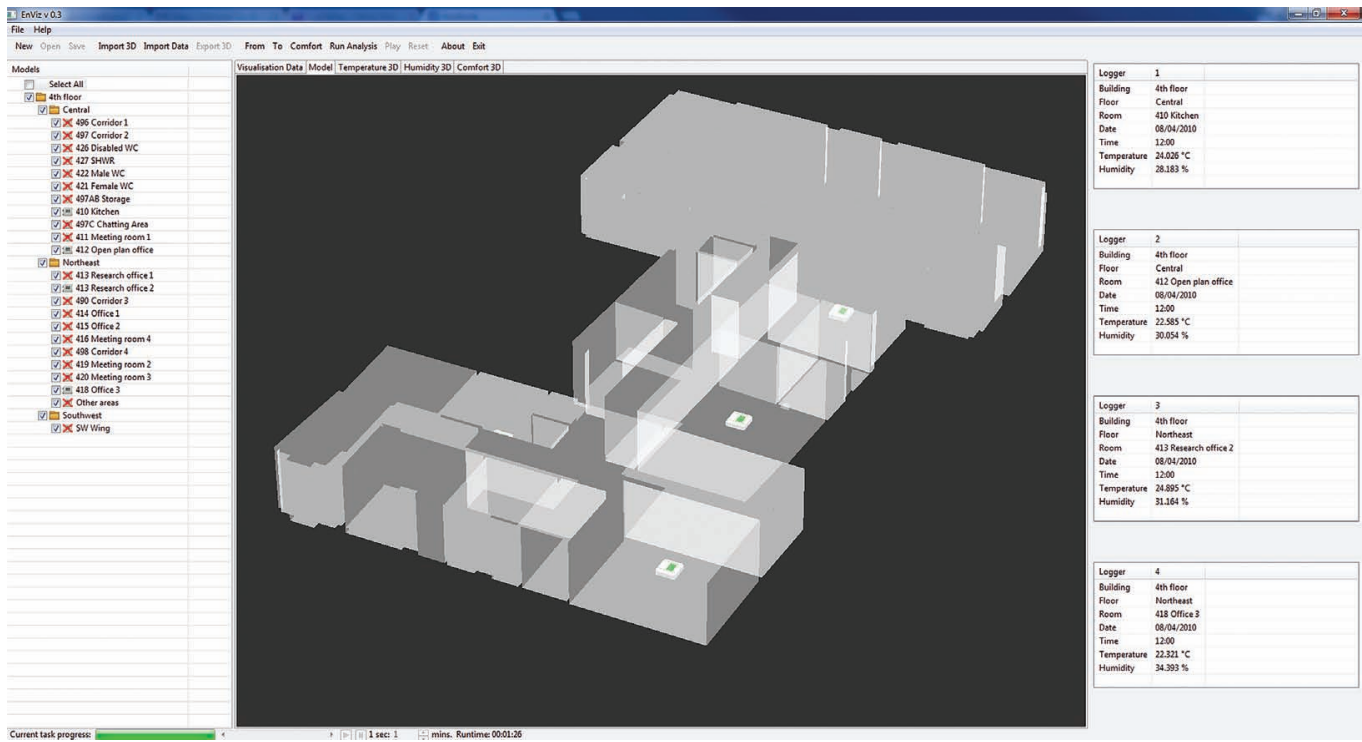

Figure 1. Sample snapshot of the EnViz application showing the locations of data loggers

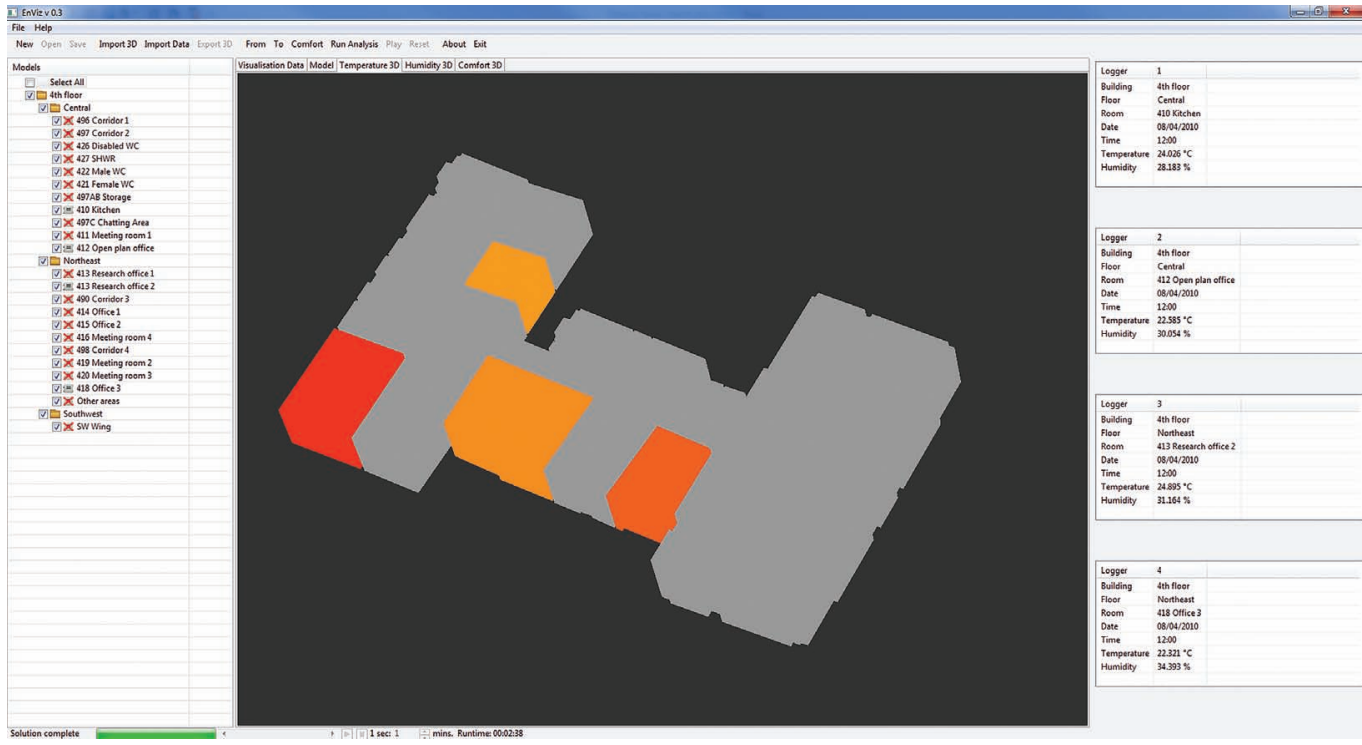

Figure 2. Sample snapshot of the EnViz application showing temperature of spaces

The EnViz testing programme involved modelling and testing three different examples of different scales and building typologies. The usability testing was in the form of eight workshops with a total of 89 participants which took place in three venues in the UK and Mexico. The response accuracy of the participants was measured directly, while mental effort was gauged indirectly through user self-reporting in questionnaires. In these experiments, the participants had increased response accuracy when using EnViz compared to that when using the traditional spreadsheet form (despite the users not having used the application before), and there was a clear preference in using the application to examine the data, as opposed to using Excel. The results were documented extensively in a journal paper (Patlakas et al., 2014).

\subsection{Theoretical framework}

The theoretical framework the authors are employing is based on the study of Hsin-Yuan Huang and Soman (2013), who gave a 


\section{Offprint provided courtesy of www.icevirtuallibrary.com Author copy for personal use, not for distribution}

detailed method for the design of gamification systems in an educational setting. This method involves a five-step process (Figure 3).

Applying this process to achieve the results described in Table 1, the authors devised the following process.

(a) Audience and context. The target audience is split into two categories

- non-experts, represented by first-year undergraduate students in built environment programmes

- entry-level specialists, represented by post-graduate students with a master of science degree in environmental design, who have already received training in POE processes.

The context would be the HE courses that the players would be attending. Taking part in the game would be fully optional without any penalty to students' course assessments, grades and so on.

(b) Objectives. The objectives and the actions through which those would be achieved are presented in detail in Tables 1 and 2.

(c) Structure of the experience. First, the players will be introduced to fundamental POE concepts in a 30-min seminar, in order to understand the context. This will be followed by a demonstration of the EnViz software with a trial model, in order to be able to use a key environment of the game. The narrative and rules of the game will then be explained. The core gaming activity will then take place. Finally, the players will be asked to complete a questionnaire providing feedback on the two types of activities. The structure of the experience is summarised in Figure 4. (d) Identifying resources. The resources available are

n university personal computer laboratories with the EnViz software

- basic programming/scripting (no dedicated budget for a fully developed game)

- standard stationery.

(e) Applying gamification elements. The game is point based, devised around a hypothetical scenario of a simplified real-life problem. Players are provided with sketches of floor plans of a real-world building (Figure 5). They are also provided with POE data in two formats. In the first half of the game, they are given Excel files with the source data, as exported from data loggers. In the second half, they are provided with the EnViz software with appropriate source files.

The authors' approach was further informed by the work of Dubbels (2013), who defined three dimensions for gamification analysis. These are: process (story against narrative); interpretation (diegesis against mimesis); and purpose (coherence against ambiguity). As the targets were highly specific and the gamified domain highly specialised, the game needed to emphasise coherence and guide the player through a structured process. The choices within the Dubbels matrix are summarised in Table 3. The specifics of Dubbels's process are outside the scope of this paper, and interested readers are advised to refer to the original work.

Further recommendations from Dubbels (2013) which were of interest to the authors during the design stage involved social interdependence, aesthetics and the utilisation of reward-action contingencies (Racs). Interdependence was addressed through the introduction of a 'hall of fame' element: top-performing players would have their names and scores publicised to the whole group.

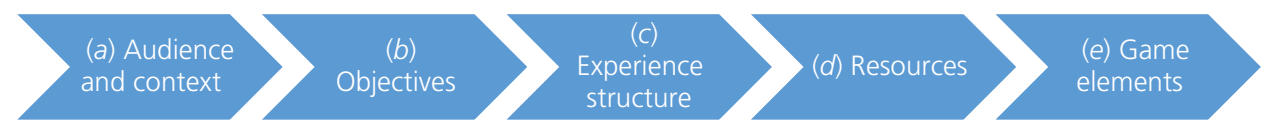

Figure 3. A process for effective gamification of a concept, adapted from Hsin-Yuan Huang and Soman (2013)

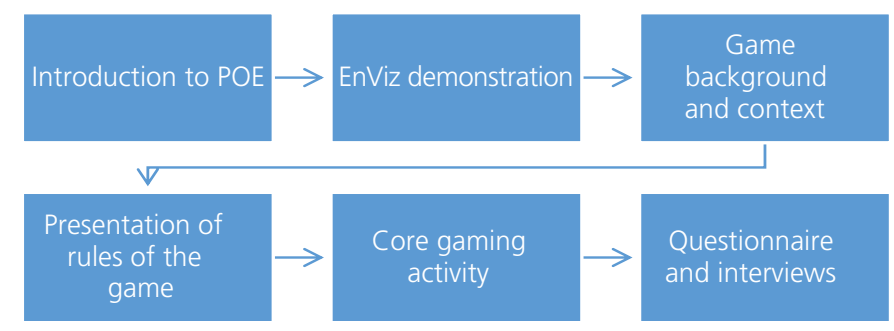

Figure 4. Structure of the game experience 


\section{Offprint provided courtesy of www.icevirtuallibrary.com Author copy for personal use, not for distribution}

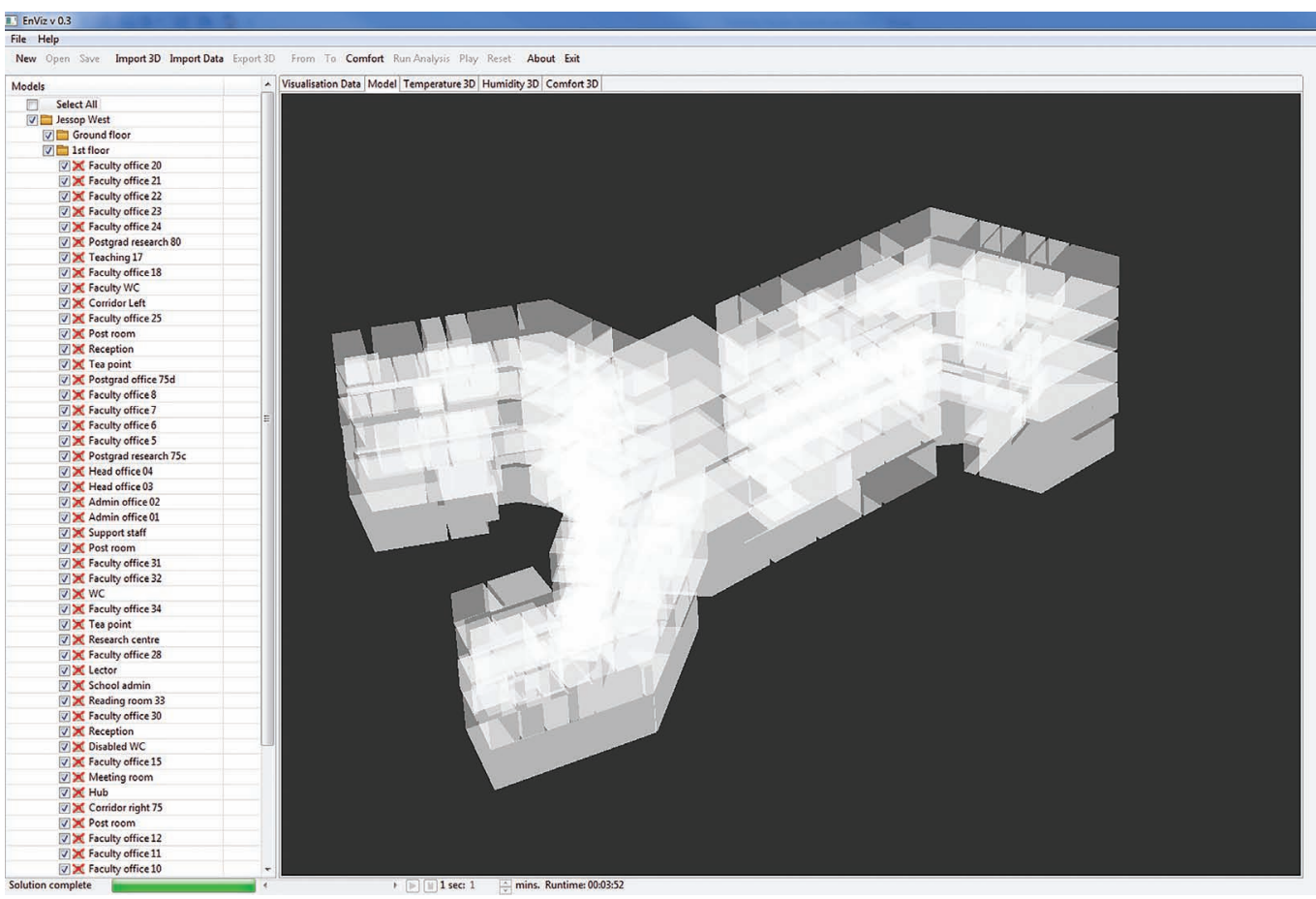

Figure 5. Visualisation of the building used in the game

Table 3. Game analysis using the Dubbels matrix

\begin{tabular}{lcc} 
Dimension & \multicolumn{2}{c}{ Action } \\
$X=$ process & Story & Narrative \\
$Y=$ interpretation & Diegesis & $\checkmark$ \\
$Z=$ purpose & $\checkmark$ & Mimesis \\
& Coherence & Ambiguity \\
& $\checkmark$ &
\end{tabular}

Moreover, when applicable, top-performing players would receive a very small bonus in their overall course grade for that semester. This would be of a positive nature only (i.e. students who chose not to play the game would not be penalised in their grade and could still achieve 100\%), and it would not decide if a student passes or fails a module (i.e. it would be applicable only for a student who would pass the module without it). The authors were limited in their capacity to enhance the aesthetics of the basic game environment, due to limited resources, and thus had to rely on what they could build themselves; however, in this they found support from Kapp (2012), who suggested that the real power of games lies in non-superficial elements such as engagement and problem-solving.

Engagement remained a key issue. It is a truism that most players will not finish most games; one estimate has $90 \%$ of players not finishing video games due to short attention spans and a small amount of leisure time in a world with a wide range of leisure options (Snow, 2011). This engagement-driving characteristic, sometimes referred to as 'good gameplay' among video game designers, however, is usually elusive. Racs appear as a potentially very useful feature, but they significantly increase the need for resources in terms of programming time and cost. As such, in the first iteration of the game, the authors used practically no Racs.

\subsection{Narrative and game mechanics}

The scenario given to the players assumed that the given building was found to be problematic in a number of areas. A POE survey was commissioned in all the areas that were supposed to fail in achieving the standard temperature and/or relative humidity criteria for thermal comfort identified by the Chartered Institute of Building Services Engineers. The players were given the role of a facilities manager whose aim is to 'fix' different areas of the building in the best possible way, within the constraints of an allocated budget.

The main rules of the game were as follows.

1. The budget was approximately $25 \%$ of what would be required to fix the entire building; hence, the players were required to prioritise the areas with the greatest percentage of failure. Points were awarded based on the percentage of actual failure of an area. For example, if a player decided to fix an area that failed to reach the required temperature $75 \%$ of the time, he or she would be awarded 75 points.

2. The cost to fix each area was proportional to its surface (based on area categorisations), and the points awarded were 


\section{Offprint provided courtesy of www.icevirtuallibrary.com Author copy for personal use, not for distribution}

also similarly proportional (if an area was four times as large as the base area category and it failed $75 \%$ of the time, the student would be awarded $75 \times 4=300$ points). Effectively, the requirement of the game was for a player to identify which areas performed worse and prioritise them accordingly.

In the first iteration of the game, areas were also given 'importance' coefficients based on their use. As such, corridors were awarded a multiplier of $0 \cdot 1$ (10\% of points), secondary spaces a multiplier of 0.5 (50\% points) and office spaces and classrooms a multiplier of 0.5 . Penalty points were applied to players who went over budget that negated any benefit from breaking the rule; this intended to add an additional puzzle element, requiring the players to focus on optimising their budget use, as well as provide an insight into the choices faced by facilities managers.

The total sum of the points followed the equation

\section{1. $P=i \times \alpha \times F$}

where $P$ is the points awarded, $i$ is the importance of the area $(0 \cdot 0-1 \cdot 0), \alpha$ is the area factor $(1-8)$ and $F$ is the failure rate of the space $(0-100)$.

\subsection{Pilot study}

A pilot workshop was run at a UK university with eight first-year students enrolled on a bachelor of arts (BA) in architectural technology programme. The students executed both parts of the game and completed a questionnaire recording their views. The results of the pilot workshop were, however, inconclusive. When using EnViz, students performed generally better; however, in both cases most students were heavily penalised for going over budget. Also, some students appeared to ignore completely the importance factor of a space and concentrated on circulation spaces. Thus, it was difficult to gauge how effective each method was with regard to response time.

Qualitative feedback provided through questionnaires and informal chats after the experiment generally suggested that the students preferred to work with the $3 \mathrm{D}$ model than with spreadsheets (despite the students reporting a greater familiarity with Excel than 3D tools before the experiment).

\subsection{Game mechanics redesign}

The pilot workshop highlighted weaknesses in the game, corresponding to aspects 1 (audience and context) and 5 (game elements) of the design process.

W1: the rules were too complex for the players to understand in a short introduction session and apply successfully the first time.

W2: the complexity of the point system meant that players spent too much cognitive effort on tasks unrelated to the outcome; thus, the objectives were largely not achieved. The players were 'missing the forest for the trees'.

- W3: the lack of interactivity (lack of Racs) meant that some players quickly disengaged from the game.

W4: the lack of information about the current budget and the requirement for calculations led to further disengagement; the puzzle element that was introduced as part of the budget did not work for the particular audience.

- W5: the context meant that the audience still treated this as a type of 'university work'; the complexity in the rules and process was treated more as an exercise than a game element.

- W6: the lack of a 'game-like' environment meant that the context was taken further as 'work' as opposed to a 'game'.

Table 4 shows the key modifications that were made to the game mechanics and presentation and the weaknesses these intended to address.

\section{Main study}

\subsection{First workshop}

Two workshops were run with the new design. The first took place with a cohort of 12 students enrolled on an environmental design and engineering masters programme at a UK university. All the members of this group had already taken a semester-long module covering POE and thus represented the 'entry-level specialists' segment of the target audience. The workshop was fully voluntary and took place outside taught modules; as such, no extra marks could be awarded

\section{Table 4. Rule modifications}

\begin{tabular}{|lll}
\hline Modification & \multicolumn{1}{c}{ Details } & $\begin{array}{c}\text { Corresponds to } \\
\text { weaknesses }\end{array}$ \\
\hline Improve presentation & $\begin{array}{l}\text { The rules would be discussed more clearly, highlighting to the students that this } \\
\text { exercise is unrelated to marks and schoolwork (positive outcomes only). } \\
\text { Tule simplification } \\
\text { The space coefficient was removed. All spaces would have equal importance. } \\
\text { The 'budget penalty' was also removed (see below), thus significantly reducing the } \\
\text { cognitive load for players. }\end{array}$ & W1, W5 \\
An interactive game environment was built for logging the points (Figure 6). With \\
this, the players see immediately the area factor of a space and the cost effects that \\
the space has. Thus, players could not go over budget. \\
Gamultaneously, this introduces a Rac element, as well an allusion to game aesthetics \\
(although both at a rather rudimentary stage).
\end{tabular}




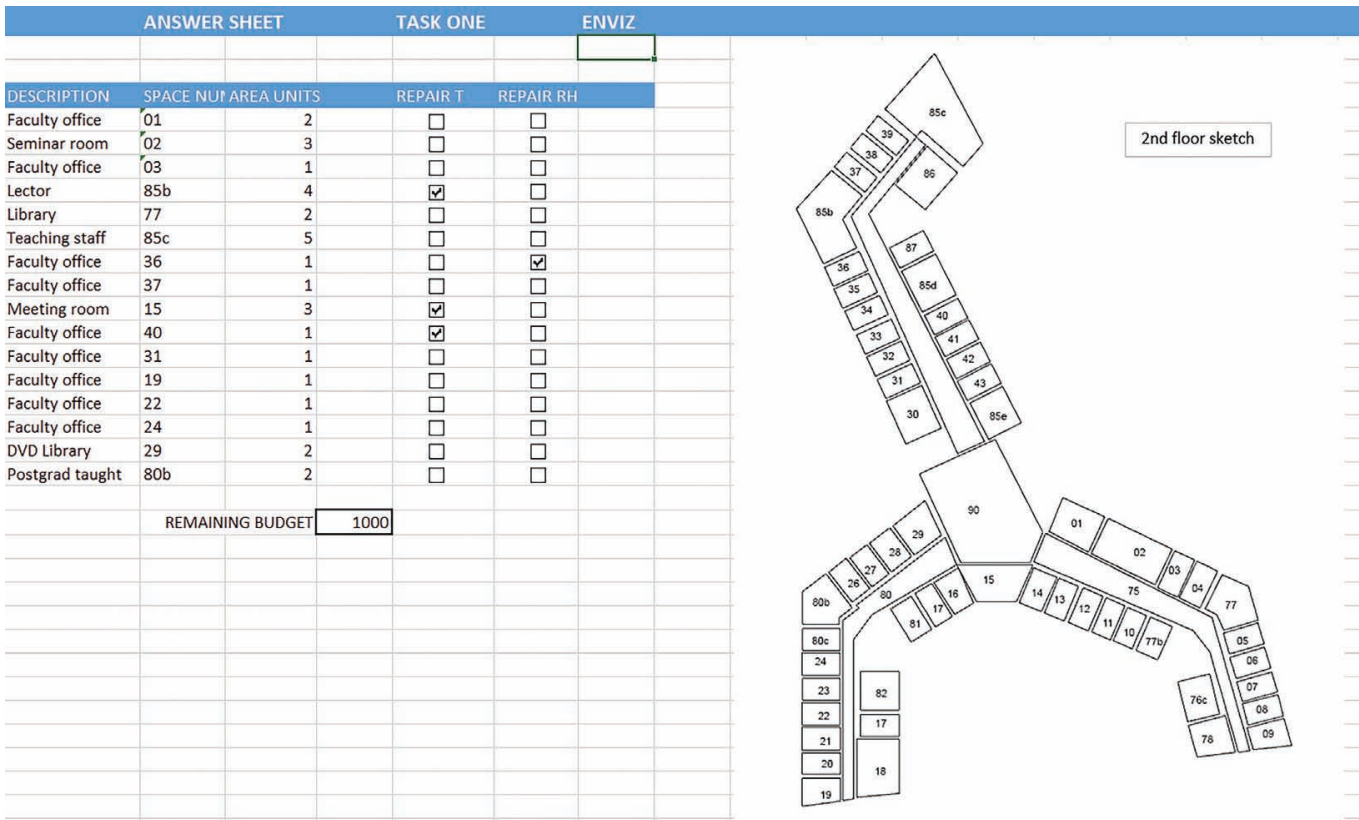

Figure 6. Snapshot of the interactive game environment given to the students

for top performers and the incentives for committing to the game were lower. The top three students would have their scores published on the virtual learning environment of the related module. Potentially due to the low incentives to committing to the game, some students did not complete one of the components, did not engage fully or broke the core rules (e.g. collaborated on one or more activities). All students were nevertheless allowed to remain for the entire duration as the educational benefits for the students were considered more important than strict enforcement of the rules (priority of intended results 2 and 3 over 1 ).
Among those who completed both components according to the rules, there was a marginally better performance when using EnViz, of approximately $7 \cdot 5 \%$ when comparing averages (Figure 7). Qualitatively, players rated EnViz as a preferred method of work in most categories (Figures 8 and 9). The players were asked to rate the two approaches in the following categories

- easy to learn

- easy to use

- allows the player to identify the required data easily

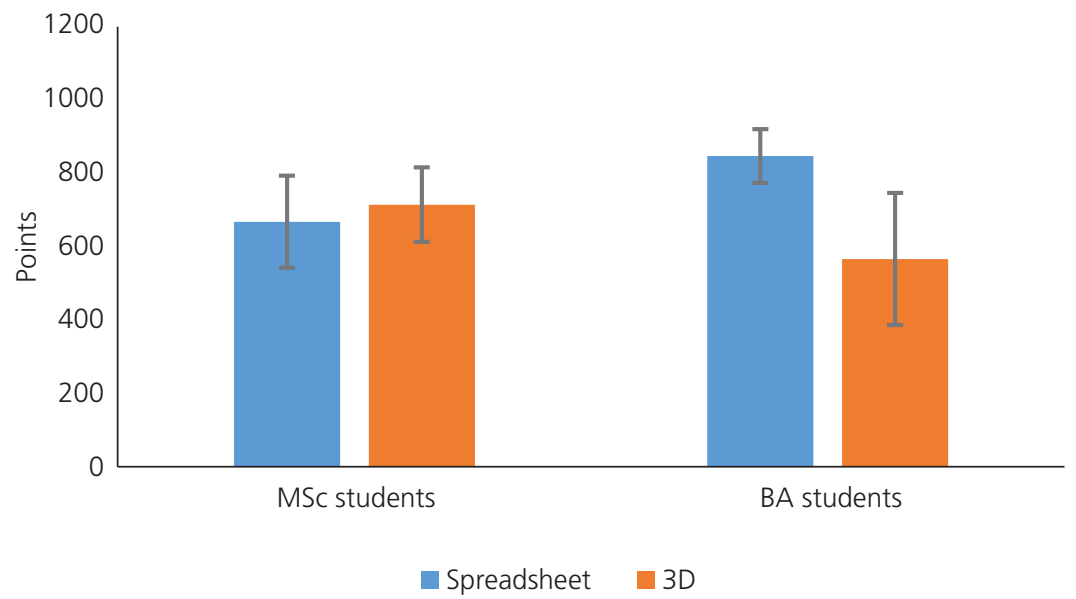

Figure 7. Points scored by each student group (average with standard deviation) 


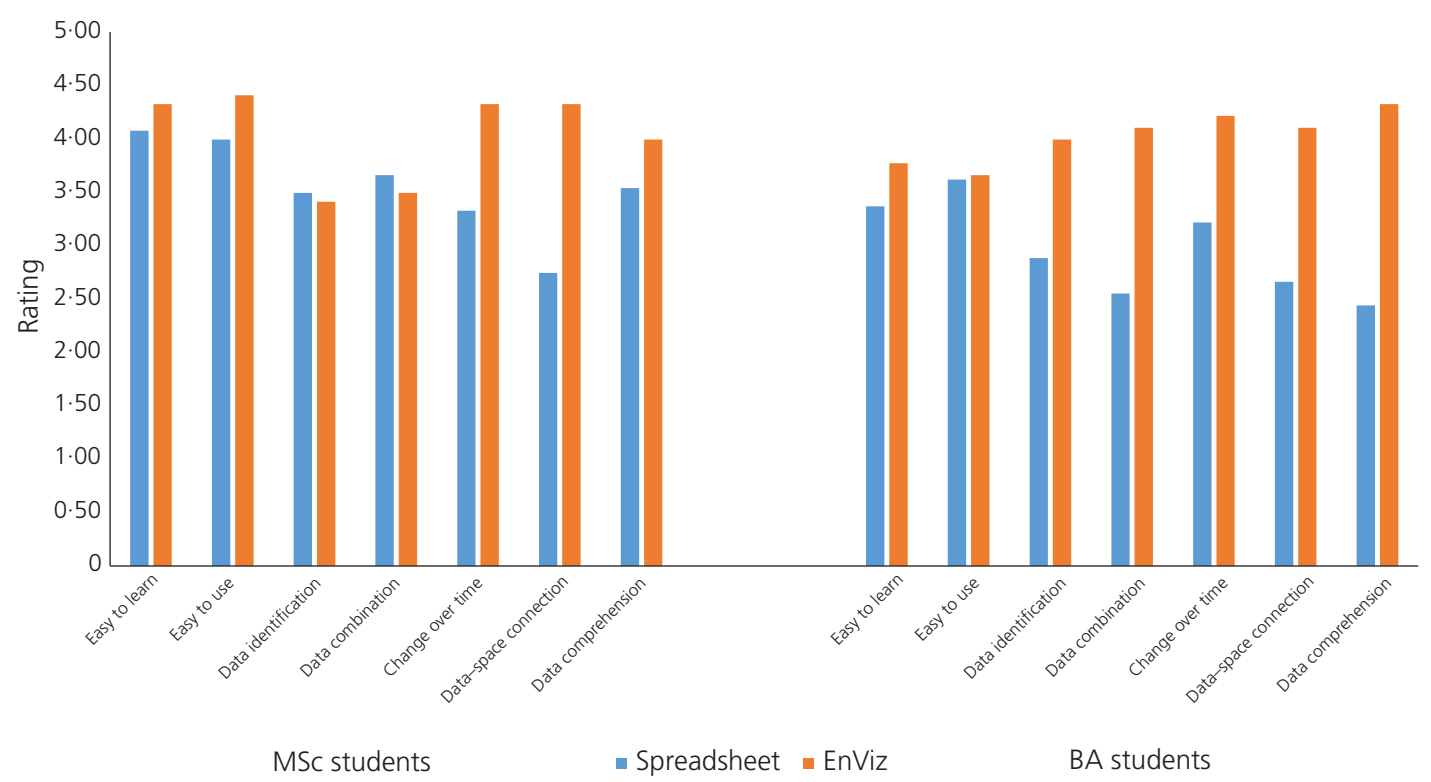

Figure 8. Ratings players gave on the two types of systems on different categories

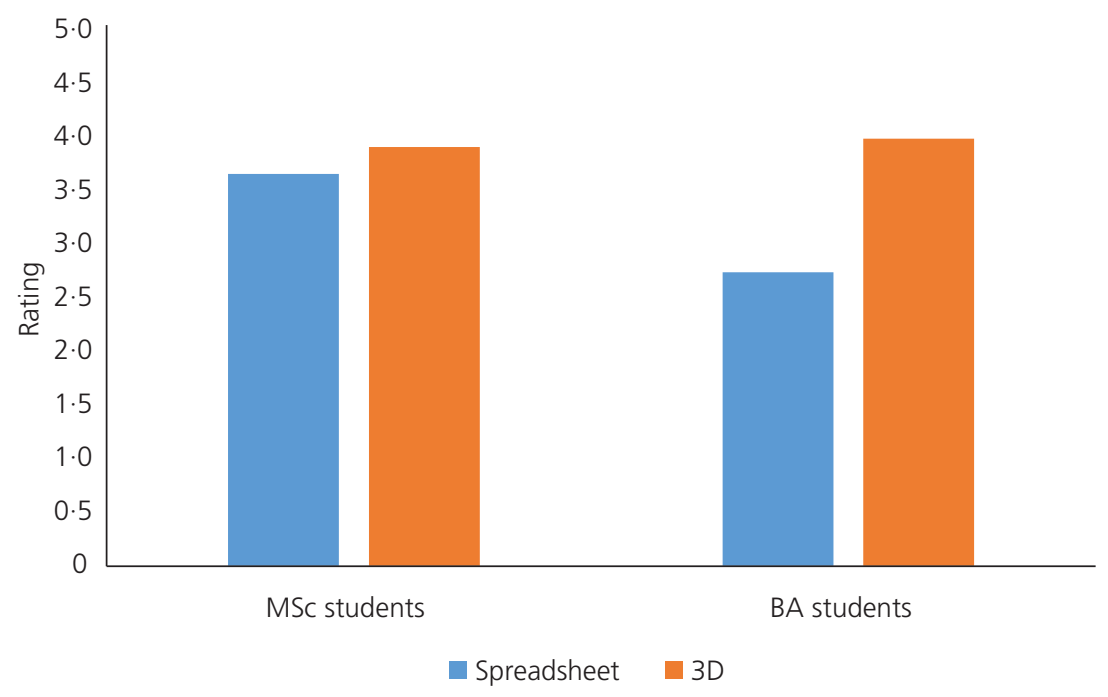

Figure 9. Overall ratings the players gave to the two approaches

allows the player to combine different pieces of information easily

- allows the player to evaluate the change over time easily

- helps the player understand how the data are connected to the space

- helps the player appreciate what is actually going on in the building.

Finally, there was a separate entry indicated as 'satisfied overall'.
The scale was $1-5$, with 1 being the most negative and 5 the most positive.

\subsection{Second workshop}

A second workshop was run with a cohort of nine BA students (first-year architectural technology), who represented the "nonexperts' segment of the target audience. The brief rules and game environment were the same as those in the first workshop. Issues of engagement with learning the software were reflected in the 


\section{Offprint provided courtesy of www.icevirtuallibrary.com Author copy for personal use, not for distribution}

results, with two students not completing one or both tasks, while three more scored very low when using EnViz, suggesting that they did not engage with learning the software (something visible during the workshop). As a result, the average scores of the students when using EnViz were significantly lower (33\%) (Figure 7). All students were more familiar with Excel than with 3D modelling, which could thus influence the results. However, when it came to evaluating the two applications, all students rated EnViz more highly than the spreadsheet-based method while they found that it allowed them to work better in all aspects (Figures 8 and 9). It should be noted that these opinions were expressed anonymously, in order to allow students to express their views candidly.

From a teaching perspective, while there were issues with engagement in learning the software, which affected performance, as discussed earlier, it is important to note that most students appeared to enjoy the activity. The undergraduate students who completed these workshops as part of a taught module appeared to have a better grasp of POE compared to students from previous years, as evidenced in end-of-year assessments. They have also talked favourably about the activity in informal discussions during the year. As the sample is very small and the results of the POE segment fall within a greater report, a quantitative study was judged to be of little importance and benefit. Accordingly, the results should be viewed as tentative, and replications with larger sample sizes and stronger financial incentives (Smith, 1982) are needed to establish their robustness and validity. This is particularly so given current research indicating that new empirical results should be viewed as tentative (Maniadis et al., 2014; Open Science Collaboration, 2015).

\section{Discussion, conclusions and directions for further research}

This paper presents the development of a simple building performance game. The results from the gamification of this process were intended to affect both the players and the developers. The players were intended to understand better issues relating to building performance, POE surveys and facilities management, as well as be introduced to the research agenda of the developers. For the developers, the objectives covered both the mentioned teaching and learning aspects, as well as collecting evidence with regard to gamified processes.

The experience demonstrated both the advantages and challenges of gamification, in agreement with the experiences reported in the literature. The development of the game, informed by Hsin-Yuan Huang and Soman's (2013) system, allowed for a straightforward transfer of building performance concepts to a gaming experience.

The main advantage of the game approach appeared to be a generally greater interest from the students in the topic. It is characteristic that most students engaged for a 90-min period in a topic which, when delivered in seminar form in previous years, did not appear to hold equal interest. The event also appeared to be more memorable to the students, probably due to the difference in format from the more standardised teaching and learning activities that they covered in the rest of the year.

However, gamification should not be viewed as a panacea. The pitfalls identified by Kapp (2012) appeared to apply in this case as well. The game needs to be structured carefully to avoid overloading the students with information (as in the pilot study) and be entertaining and intuitive while still enabling students to achieve the learning objectives. The use of Racs, as highlighted by Dubbels (2013), is fundamental in order to keep players engaged. It is telling that the introduction of even a rudimentary Rac element in the main study considerably improved the players' engagement and capacity to complete the work compared to the pilot study. It is, however, important to highlight the game development overheads that this places on the party that wants to set up the gamified process. No individual researcher or HE teacher is likely to have the resources required to design a game that approaches the state of the art in other industries, in particular the entertainment one. One way to address this could be the pooling of resources among researchers and/or institutions to develop one game, applicable to all. This, however, runs contrary to the approach typically adopted by the research and HE communities and, as such, might not be feasible in the near future.

Player engagement is a key topic in all types of games, and more so for a gamified process. In the exercise presented in this paper, while gamification did appear to lead to greater engagement, some students still appeared to need appropriate incentives to commit fully. In pedagogical parlance, students are often 'strategic' in their choice of engagement with a topic; thus, at least some will not engage with something not tied to assessment. The financial incentives suggested by Smith (1982) which have been widely adopted by social science researchers could be a good first start. This, however, could create a controversy with regard to this still being a game and not simply a ludic simulation. However, technical topics with a teaching purpose might by necessity fall into the grey area between ludic simulations and 'true' games.

A different intended result of the gamified process was to allow comparison between the spreadsheet-based and the 4D visualisation methods; in this case it was only partially achieved. The small sample, the different student profiles and the different levels of engagement meant that the results were different and had significant standard deviation. Thus, the pilot study and the first workshop seemed to follow largely the results of the more rigorous surveys reported earlier. The second workshop, however, showed that most students did not engage with the visualisation software sufficiently to enable direct comparison. This is to be expected to an extent; despite the conversation of the so-called digital natives in recent years in the pedagogic community, software fatigue appears to be a phenomenon across almost all age brackets. 


\section{Offprint provided courtesy of www.icevirtuallibrary.com Author copy for personal use, not for distribution}

It is interesting, however, that all students preferred working with the $4 \mathrm{D}$ visualisation method, irrespective of their degree of attainment, which also agrees with previous studies. This tentatively suggests that there are potentially significant benefits in visualising large data sets from buildings in creative and innovative ways, enabling non-specialists to engage with them more easily. If the aspiration of POE studies becoming a standard part of the building process is going to be realised, their outputs should be easily communicable and comprehensible by all stakeholders and not just the domain of specialist practitioners.

The overarching objective of the EnViz project is to examine whether 4D visualisation improves the quality of decisions that influence environmental properties of buildings. One line of enquiry that the authors are considering is to examine the effects of gamification when some methodologies from behavioural disciplines such as experimental economics are introduced (Smith, 1982). In particular, offering financial incentives for good performance could increase cognitive effort and improve commitment to the game. Furthermore, ensuring a sufficient power of the experimental design by increasing the sample sizes will allow for formal statistical analysis and thus produce more robust results.

\section{Acknowledgements}

The authors would like to thank Dr Zacharias Maniadis, associate professor in economics at the University of Southampton, for his very helpful insights into the role of the building user as a consumer and for pointing them towards the relevant literature. In addition the authors benefited from Dr Maniadis's attendance of the pilot study and his feedback on optimising the gamified process for the main study.

The authors would also like to thank Dr Darren Roberts, who led the software development of EnViz.

\section{REFERENCES}

Akerlof GA (1970) The market for lemons: quality uncertainty and the market mechanism. Quarterly Journal of Economics 84(3): 488-500.

Arenas F and Stricker A (2013) Gamification strategies for developing Air Force officers. Learning Solutions Magazine, 17 June. See http://www. learningsolutionsmag.com/articles/1190/gamification-strategies-fordeveloping-air-force-officers (accessed 06/10/2016).

Attali $Y$ and Arieli-Attali M (2015) Gamification in assessment: do points affect test performance? Computers \& Education 83: 57-63, http://dx. doi.org/10.1016/j.compedu.2014.12.012.

Aydin S, Lo TT and Schnabel MA (2014) Gamification of shape grammars collaborative and participatory mass-housing design for Kashgar old town. Fusion-Proceedings of the 32nd eCAADe Conference, Newcastle upon Tyne, UK, vol. 1, pp. 603-612.

Bajdor P and Dragolea I (2011) The gamification as a tool to improve risk management in the enterprise. Annales Universitatis Apulensis: Series Oeconomica 13(2): 574-583.

Barata G, Gama S, Jorge J and Gonçalves D (2013) Engaging engineering students with gamification. Proceedings of the 5th International Conference on Games and Virtual Worlds for Serious Applications (VS-GAMES). Institute of Electrical and Electronics Engineers, Piscataway, NJ, USA, pp. 1-8.
Bertuzzi JZ and Zreik K (2011) Mixed reality games-augmented cultural heritage. Proceedings of the SIGRADI Conference, Santa Fe, Argentina, pp. 304-307.

Bogost I (2015) Why gamification is bullshit. In The Gameful World: Approaches, Issues, Applications (Walz SP and Deterding S (eds)). MIT Press, Cambridge, MA, USA, pp. 65-80.

Boomsma C, Goodhew J, Goodhew S and Pahl S (2016) Improving the visibility of energy use in home heating in England: thermal images and the role of visual tailoring. Energy Research \& Social Science 14 111-121, http://dx.doi.org/10.1016/j.erss.2016.01.005.

Bordass B (2004) Energy performance of non-domestic buildings: closing the credibility gap. Proceedings of the 2004 Improving Energy Efficiency of Commercial Buildings Conference, Frankfurt, Germany, pp. 1-10.

Bordass B and Leaman A (2005) Making feedback and post-occupancy evaluation routine 1: a portfolio of feedback techniques. Building Research \& Information 33(4): 347-352, http://dx.doi.org/10.1080/ 09613210500162016.

Bourgeois D, Reinhart C and Macdonald I (2006) Adding advanced behavioural models in whole building energy simulation: a study on the total energy impact of manual and automated lighting control. Energy and Buildings 38(7): 814-823, http://dx.doi.org/10.1016/j. enbuild.2006.03.002.

Chang TW (2004) Supporting design learning with design puzzles. In Recent Advances in Design and Decision Support Systems in Architecture and Urban Planning (van Leeuwen JP and Timmermans HJP (eds)). Springer, Dordrecht, the Netherlands, pp. 293-307.

Chen HM, Lin CW, Hsieh SH et al. (2012) Persuasive feedback model for inducing energy conservation behaviors of building users based on interaction with a virtual object. Energy and Buildings 45: 106-115, http://dx.doi.org/10.1016/j.enbuild.2011.10.029.

Clevenger C and Haymaker J (2006) The impact of the building occupant on energy modeling simulations. Proceedings of the Joint International Conference on Computing and Decision Making in Civil and Building Engineering, Montreal, QC, Canada.

Cohen I, Turrin M, Heinzelmann F and Welzner I (2013) The human factor - introducing game mechanics to computerized home automation systems. Computation and Performance - Proceedings of eCAADe 2013, Delft, Netherlands, pp. 175-184.

Cruickshank HJ and Fenner RA (2007) The evolving role of engineers: towards sustainable development of the built environment. Journal of International Development 19(1): 111-121, http://dx.doi.org/10.1002/ jid. 1352.

Deterding S, Sicart M, Nacke I, O'Hara K and Dixon D (2011) Gamification using game-design elements in non-gaming contexts. Proceedings of CHI '11 Extended Abstracts on Human Factors in Computing Systems, Vancouver, BC, Canada, pp. 2425-2428.

De Wilde P (2014) The gap between predicted and measured energy performance of buildings: a framework for investigation. Automation in Construction 41: 40-49, http://dx.doi.org/10.1016/j.autcon.2014.02. 009.

De Wilde P and Tian W (2009) Identification of key factors for uncertainty in the prediction of the thermal performance of an office building under climate change. Building Simulation 2(3): 157-174, http://dx. doi.org/10.1007/s12273-009-9116-1.

Ding GK (2008) Sustainable construction - the role of environmental assessment tools. Journal of Environmental Management 86(3): 451-464, http://dx.doi.org/10.1016/j.jenvman.2006.12.025.

Dubbels B (2013) Gamification, serious games, ludic simulation, and other contentious categories. International Journal of Gaming and Computer-mediated Simulations 5(2): 1-19, http://dx.doi.org/10.4018/ jgcms.2013040101.

Erenli K (2013) The impact of gamification - recommending education scenarios. International Journal of Emerging Technologies in Learning 8: $15-21$. 


\section{Offprint provided courtesy of www.icevirtuallibrary.com Author copy for personal use, not for distribution}

Fink HS (2011) Promoting behavioral change towards lower energy consumption in the building sector. Innovation: the European Journal of Social Science Research 24(1-2): 7-26.

Finkelstein A and Poterba J (2004) Adverse selection in insurance markets: policyholder evidence from the UK annuity market. Journal of Political Economy 112(1): 183-208, http://dx.doi.org/10.3386/w8045.

Frankfurt HG (2005) On Bullshit. Princeton University Press, Princeton, NJ, USA.

Gill ZM, Tierney MJ, Pegg IM and Allan N (2010) Low-energy dwellings: the contribution of behaviours to actual performance. Building Research \& Information 38(5): 491-508, http://dx.doi.org/10.1080/ 09613218.2010.505371

Grossman GM and Helpman E (2001) Special Interest Politics. MIT Press, Cambridge, MA, USA.

Gustafsson A, Katzeff C and Bang M (2009) Evaluation of a pervasive game for domestic energy engagement among teenagers. Computers in Entertainment 7(4): 54, http://dx.doi.org/10.1145/1658866.1658873.

Hamari J, Koivisto J and Sarsa H (2014) Does gamification work? - A literature review of empirical studies on gamification. Proceedings of the 47th Hawaii International Conference on System Sciences (HICSS). Institute of Electrical and Electronics Engineers, Piscataway, NJ, USA, pp. 3025-3034

Hoes P, Hensen JLM, Loomans M, De Vries B and Bourgeois D (2009) User behavior in whole building simulation. Energy and Buildings 41(3): 295-302, http://dx.doi.org/10.1016/j.enbuild.2008.09.008.

Hsin-Yuan Huang W and Soman D (2013) A Practitioner's Guide to Gamification of Education. Rotman School of Management, Toronto, ON, Canada. See http://inside.rotman.utoronto.ca/ behaviouraleconomicsinaction/files/2013/09/ GuideGamificationEducationDec2013.pdf (accessed 22/11/2016).

Huang W, Eades P and Hong SH (2009) Measuring effectiveness of graph visualisations: a cognitive load perspective. Information Visualisation 8(3): 139-152, http://dx.doi.org/10.1057/ivs.2009.10

Hui SC and Cheung KP (1999) Developing a web-based learning environment for building energy efficiency and solar design in Hong Kong. Solar Energy 67(1): 151-159, http://dx.doi.org/10.1016/S0038092X(00)00041-4.

Huotari K and Hamari J (2012) Defining gamification: a service marketing perspective. Proceedings of the 16th International Academic Mindtrek Conference, Tampere, Finland, pp. 17-22.

IPCC (Intergovernmental Panel on Climate Change) (2014) Climate Change 2014 - Impacts, Adaptation and Vulnerability: Regional Aspects. Cambridge University Press, Cambridge, UK.

Kapp KM (2012) The Gamification of Learning and Instruction: Gamebased Methods and Strategies for Training and Education. Wiley, San Francisco, CA, USA.

Karlan D and Zinman J (2009) Observing unobservables: identifying information asymmetries with a consumer credit field experiment. Econometrica 77(6): 1993-2008, http://dx.doi.org/10.3982/ECTA5781.

Kibert CJ (2002) Policy instruments for a sustainable built environment. Journal of Land Use \& Environmental Law 17(2): 379-394.

King D, Greaves F, Exeter C and Darzi A (2013) Gamification: influencing health behaviours with games. Journal of the Royal Society of Medicine 106(3): 76-78, http://dx.doi.org/10.1177/ 0141076813480996

Koster R (2013) Theory of Fun for Game Design. O'Reilly Media, Sebastopol, CA, USA.

Landers RN and Callan RC (2011) Casual social games as serious games: the psychology of gamification in undergraduate education and employee training. In Serious Games and Edutainment Applications (Ma M, Oikonomou A and Jain LC (eds)). Springer, London, UK, pp. 399-423.

Liang CH and Chang TW (2006) Towards a playful design environment DiGame. Proceedings of CAADRIA 2006, Kumamoto, Japan, pp. 187-196.
Loewenstein G, Sunstein CR and Golman R (2014) Disclosure: psychology changes everything. Annual Review of Economics 6: 391-419, http:// dx.doi.org/10.1146/annurev-economics-080213-041341.

Maniadis Z, Tufano F and List J (2014) One swallow doesn't make a summer: new evidence on anchoring effects. American Economic Review 104(1): 277-290, http://dx.doi.org/10.1257/aer.104.1.277.

McCallum S (2012) Gamification and serious games for personalized health. Studies in Health Technology and Informatics 177: 85-96.

Menezes AC, Cripps A, Bouchlaghem D and Buswell R (2012) Predicted vs. actual energy performance of non-domestic buildings: using postoccupancy evaluation data to reduce the performance gap. Applied Energy 97: 355-364, http://dx.doi.org/10.1016/j.apenergy.2011.11.075.

Milgrom P (2008) What the seller won't tell you: persuasion and disclosure in markets. Journal of Economic Perspectives 22(2): 115-131, http://dx.doi.org/10.1257/jep.22.2.115.

Mollick ER and Rothbard N (2014) Mandatory Fun: Consent, Gamification and the Impact of Games at Work. The Wharton School of the University of Pennsylvania, Philadelphia, PA, USA.

Muntean Cl (2011) Raising engagement in e-learning through gamification. Proceedings of 6th International Conference on Virtual Learning, Bucharest, Romania, pp. 323-329.

Murray PE and Cotgrave AJ (2007) Sustainability literacy: the future paradigm for construction education? Structural Survey 25(1): 7-23.

Open Science Collaboration (2015) Estimating the reproducibility of psychological science. Science 349(6251): aac4716, http://dx.doi.org/ 10.1126/science.aac4716.

Ortiz O, Castells F and Sonnemann G (2009) Sustainability in the construction industry: a review of recent developments based on LCA Construction and Building Materials 23(1): 28-39, http://dx.doi.org/ 10.1016/j.conbuildmat.2007.11.012.

Patlakas P, Santacruz HB and Altan H (2014) Visualising the environmental conditions of buildings. Proceedings of the Institution of Civil Engineers - Civil Engineering 167(5): 56-64, http://dx.doi. org/10.1680/cien.13.00014.

Pedreira O, García F, Brisaboa N and Piattini M (2015) Gamification in software engineering - a systematic mapping. Information and Software Technology 57: 157-168, http://dx.doi.org/10.1016/j.infsof. 2014.08.007.

Salen K and Zimmerman E (2004) Rules of Play: Game Design Fundamentals. MIT Press, Cambridge, MA, USA.

Santos Silva A and Ghisi E (2014) Uncertainty analysis of user behaviour and physical parameters in residential building performance simulation. Energy and Buildings 76: 381-391, http://dx.doi.org/10. 1016/j.enbuild.2014.02.070.

Savov A, Tessmann O and Nielsen SA (2016) Sensitive assembly: gamifying the design and assembly of façade wall prototypes. International Journal of Architectural Computing 14(1): 30-48.

Schwartz Y and Raslan R (2013) Variations in results of building energy simulation tools, and their impact on BREEAM and LEED ratings: a case study. Energy and Buildings 62: 350-359, http://dx.doi.org/10. 1016/j.enbuild.2013.03.022.

Simões J, Redondo RD and Vilas AF (2013) A social gamification framework for a K-6 learning platform. Computers in Human Behavior 29(2): 345-353.

Smith V (1982) Microeconomic systems as an experimental science. American Economic Review 72(5): 923-955.

Snow B (2011) Why Most People Don't Finish Video Games. Cable News Network, Atlanta, GA, USA. See http://edition.cnn.com/2011/tech/ gaming.gadgets/08/17/finishing.videogames.snow/ (accessed 10/10/ 2016).

Sorrell S (2003) Making the link: climate policy and the reform of the UK construction industry. Energy Policy 31(9): 865-878, http://dx.doi.org/ 10.1016/S0301-4215(02)00130-1.

Stiglitz JE and Brown EP (2000) Economics of the Public Sector. W. W. Norton, New York, NY, USA. 
Swan W, Fitton R and Brown P (2015) A UK practitioner view of domestic energy performance measurement. Proceedings of the Institution of Civil Engineers - Engineering Sustainability 168(3): 140-147, http://dx.doi.org/10.1680/ensu.14.00056.

Szabó B and Babuška I (2011) Introduction to Finite Element Analysis: Formulation, Verification and Validation. Wiley, Hoboken, NJ, USA.

Szolokay SV (2014) Introduction to Architectural Science: the Basis of Sustainable Design. Architectural Press, Oxford, UK.

Te'eni D, Carey J and Zhang P (2007) Human-Computer Interaction: Developing Effective Organisational Information Systems. Wiley, Hoboken, NJ, USA.

Thaler RH and Sunstein CR (2008) Nudge: Improving Decisions about Health, Wealth, and Happiness. Yale University Press, New Haven, CT, USA.

Ware C (2012) Information Visualization: Perception for Design. Elsevier, Waltham, MA, USA.
Wright J (2003) Introducing sustainability into the architecture curriculum in the United States. International Journal of Sustainability in Higher Education 4(2): 100-105.

Yan W and Liu G (2007) Bimgame: integrating building information modeling and games to enhance sustainable design and education. Proceedings of eCAADe 2007, FH Wiesbaden, Frankfurt, Germany, pp. 211-218.

Yan D, O'Brien W, Hong T et al. (2015) Occupant behavior modeling for building performance simulation: current state and future challenges. Energy and Buildings 107: 264-278, http://dx.doi.org/10.1016/j. enbuild.2015.08.032.

Zimmerman A and Martin M (2001) Post-occupancy evaluation: benefits and barriers. Building Research \& Information 29(2): 168-174.

\section{How can you contribute?}

To discuss this paper, please email up to 500 words to the editor at journals@ice.org.uk. Your contribution will be forwarded to the author(s) for a reply and, if considered appropriate by the editorial board, it will be published as discussion in a future issue of the journal.

Proceedings journals rely entirely on contributions from the civil engineering profession (and allied disciplines). Information about how to submit your paper online is available at www.icevirtuallibrary.com/page/authors, where you will also find detailed author guidelines. 